\title{
EVALUATION OF THE BOND STRENGTH OF AH PLUS SEALER AFTER IRRIGATION OF THE ROOT CANALS USING NANO-SILVER AND SODIUM HYPOCHLORITE
}

\author{
Yousra M. Nashaat*, Hadil A. Sabry**, Nada Omar ${ }^{* * *}$, Ahmed Negm**** \\ and Walaa Mohammed Ghoneim ${ }^{* * * * *}$
}

\begin{abstract}
The aim of this study is to evaluate the bond strength of AH Plus sealer after irrigation of the root canals using of Nano-Silver and Sodium hypochlorite. Sixty, freshly extracted, sound maxillary anterior teeth with completely formed apices and straight roots were used in this study. Each tooth was decoronated to provide approximately $16 \mathrm{~mm} \pm 1$ of root, root canals with initial apical file size \#20 were selected to approximately standardize the canal diameter. The samples were divided into two groups 30 root each according to the irrigation protocol used through instrumentation: Group A: root canal preparation was performed using the Protaper Next system during instrumentation the root canals were irrigated using Nano-Silver irrigant $0.02 \mathrm{~mol} / \mathrm{L}=2000 \mathrm{ppm}$. Group B: root canal preparation was also performed using the Protaper Next system but during instrumentation the root canals were irrigated using Sodium Hypochlorite $(\mathrm{NaOCl})$ irrigant $5.25 \%$.

Root canals of each group were then obturated using master cones of \#40/06 and AH Plus sealer in lateral condensation technique. $2 \mathrm{~mm}$ thick slices of apical, middle and coronal root portion for all samples were prepared for assessment of push out bond strength for the two groups.

Results showed that AH plus sealer had a lower value of push out bond strength ( $1.223 \pm 0.533)$ in the group irrigated using nano silver than the second group irrigated with sodium hypochlorite $(2.321 \pm 0.650)$ at the coronal third with statistically significant difference $(\mathrm{P}=0.004)$, also at the middle third it showed a lower value $(1.732 \pm 0.899)$ than the sodium hypochlorite but with no statistically significant difference, and finally at the apical third it also a lower value of push out bond strength $(2.103 \pm 1.319)$ than the other group irrigated with $\mathrm{NaOCl}(5.045 \pm 1.397)$ with statistically significant difference $(0.001)$
\end{abstract}

\footnotetext{
* Associate Professor of Endodontics, October 6 University.

** Associate Professor of Biomaterials, October 6 University.

*** Researcher, Restorative \& Dental materials department National Research Center **** Lecturer of Endodontics, Ahram Canadian University.

***** Lecturer of Endodontics, Tanta University.
} 


\section{INTRODUCTION}

Pulp and periapical diseases are caused mainly by microorganisms. Hence, the main objective of root canal treatment is to eliminate microorganisms, microbial byproducts and necrotic tissues from the root canal system. ${ }^{[1]}$

Root canal system is anatomically complex, with areas that cannot be reached with instruments. Consequently, the goal of canals cleaning is accomplished by chemical and mechanical means (chemico-mechanically) which include a combination of instrumentation and physicochemical action of endodontic irrigants. ${ }^{[2,3]}$

The rate of success of the treatment is still a problem despite the advances used in endodontic treatment. Colonization of bacteria in biofilm, smear layer formation during instrumentation, anatomical complexity and the microorganisms remained in dentinal tubules are the main causes of reinfection and failure of endodontic treatment. ${ }^{[4]}$

Several antimicrobial irrigating solutions are used in endodontic treatment. Sodium hypochorite $(\mathrm{NaOCl})$, chlorhexidine gluconate (CHX), ethylenediaminetetacetic acid (EDTA), mixture of Tetracycline isomer acid and detergent (MTAD) and ozonated water are types of irrigants used as antimicrobial solutions. Topbas et al. in 2017 described the effect of each irrigant on the success of the endodontic treatment and the recommended method for each irrigant. They concluded that, the future researches should concentrate on producing a single irrigating solution that has tissue-solubilizing properties, biocompatible, remove the smear layer and has antibacterial effect. ${ }^{[2]}$

The irrigation has an important role in lubrication, dissolution of remaining pulp tissue, mechanical washing, and most importantly is killing the microbes. ${ }^{[5]}$

Although various irrigants are available, none of them fulfill all of the ideal properties of endodontic irrigant. ${ }^{[6]}$

Sodium hypochorite $(\mathrm{NaOCl})$ is the most commonly used root canal irrigant because of its antibacterial effect and its ability to dissolve the organic debris and remaining pulp tissues. Its shortcomings include, unpleasant taste, inability to completely remove the smear layer, toxicity, the deterioration of flexural strength and bond strength between resin and dentin. ${ }^{[6,7,8]}$

Nanomaterials are defined as particles with external dimensions of $1-100 \mathrm{~nm}$, which gives them a large surface area that increase their chemical reactivity. ${ }^{[9,10]}$

The nanoparticles surface area and charge density interacts with the negatively charged bacterial cells, enhancing their antimicrobial activity. ${ }^{[1,12]}$

Monzavi et al. 2015 found that nano-MgO aqueous solutions show promising antimicrobial activity. ${ }^{[13]}$

Silver nanoparticles have several applications in dental field as they can be incorporated in restorative materials, bonding chemicals for carried reduction and prevents biofilm formation in implant materials. $[14,15]$

Javidi et al. 2014 evaluated the bactericidal effect of $\mathrm{Ca}(\mathrm{OH})_{2}$ with and without silver nanoparticles on Enterococcus faecalis. They found that the number of CFUs observed with the addition of silver nanoparticles suspension was significantly less than the number with $\mathrm{Ca}(\mathrm{OH})_{2}$ alone. ${ }^{[16]}$

Silver nanoparticles are capable of attaching to and penetrating into the cell walls of both gram +ve and gram -ve bacteria, releasing silver ions which disturb the cell function. Thus, they are used for the prevention and treatment of drug- resistant microorganisms and inhibition of the formation of biofilm. ${ }^{[17]}$

Root canal obturation is an important step for success in endodontics as it provides apical and coronal seal. The most commonly used root filling 
material is gutta-percha with sealer.

Sealers should bond to dentin to minimize leakage and improve stability of root canal filling material. Based on studies adhesion of sealers are affected by their chemical and physical characteristics, irrigation protocol and smear layer removal. ${ }^{[18,19]}$

$\mathrm{AH}$ Plus is a resin-based sealer which has acceptable physical properties and biocompatible. Previous studies have reported the positive effects of triple antibiotic paste, removing the smear layer, activating irrigation solution with ultrasonic, applying Er:YAG laser on the bond strength of this sealer. ${ }^{[18,20,21,22]}$

There are various methods for evaluating adhesion of a dental material to dentin including tensile and shear (planner interface and push-out) test. It has been suggested that push-out test may provide a better evaluation results than the conventional shear test because in push-out test, fracture occurs parallel to the dentine-bonding interface, which makes it a true shear test for parallel-sided samples. ${ }^{[23]}$

\section{MATERIALS AND METHODS}

\section{Selection and preparation of teeth:}

Sixty, recently extracted, sound maxillary anterior teeth with completely formed apices and straight roots were selected to be used in this study from the surgery clinic October 6 University. The teeth were scaled and cleaned of debris and periodontal remnants. All samples were stored in distilled water at $37^{\circ} \mathrm{C}$ until used.

Each tooth was decoronated to provide approximately $16 \mathrm{~mm} \pm 1$ of root with high speed diamond disc under water coolant system. Root canals with initial apical file size \#20 were selected to approximately standardize the canal diameter.

The working length of each sample was detected, then the samples were divided into two groups 30 root each according to the irrigation regimen through instrumentation:

Group A: root canal preparation was performed using the Protaper Next system (Dentsply Sirona) $1 \mathrm{~mm}$ shorter from the apical foramen up to size X4 (size\# 40/06). During instrumentation the root canals were irrigated using Nano-Silver irrigant $0.02 \mathrm{~mol} / \mathrm{L}=2000 \mathrm{ppm}$.

Group B: root canal preparation was performed using the Protaper Next system (Dentsply Sirona) $1 \mathrm{~mm}$ shorter from the apical foramen up to size X4 (size\# 40/06). During instrumentation the root canals were irrigated using Sodium Hypochlorite $(\mathrm{NaOCl})$ irrigant $5.25 \%$.

Irrigation for the two tested groups was performed using 30 gauge side vent needle. Finally $5 \mathrm{ml}$ of distilled water was used as a final flush for all groups after the final irrigating solutions and $5 \mathrm{~mL}$ of EDTA was used per canal to remove the smear layer. All root canals were finally dried using size\#40 paper points ${ }^{[24]}$

Root canals of each group were then filled using AH Plus sealer and master points \#40/06 according to the manufacturer's instructions in lateral condensation technique.

\section{Push-out bond strength test}

Teeth were embedded in chemical cured acrylic resin and then cross-sectioned using IsoMet 4000 microsaw Buehler USA mounting diamond disk 0.6 $\mathrm{mm}$ thickness at speed $2500 \mathrm{rpm}$ and feeding rate $10 \mathrm{~mm} / \mathrm{min}$ under water cooling. $2 \mathrm{~mm}$ thick slices of apical, middle and coronal root portion were prepared for assessment of push out bond strength. All samples were photographed and examined using stereomicroscope (Nikon MA100 Japan) to confirm absence of dentin cracks or voids of the filling materials.

The tested material was then loaded with a stainless steel plunger of a $0.9 \mathrm{~mm}$ diameter. The plunger was mounted on the upper part of a universal 


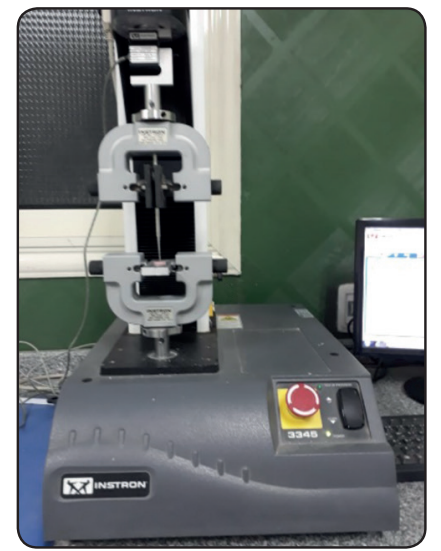

Fig. (1): Instron machine used in push out test

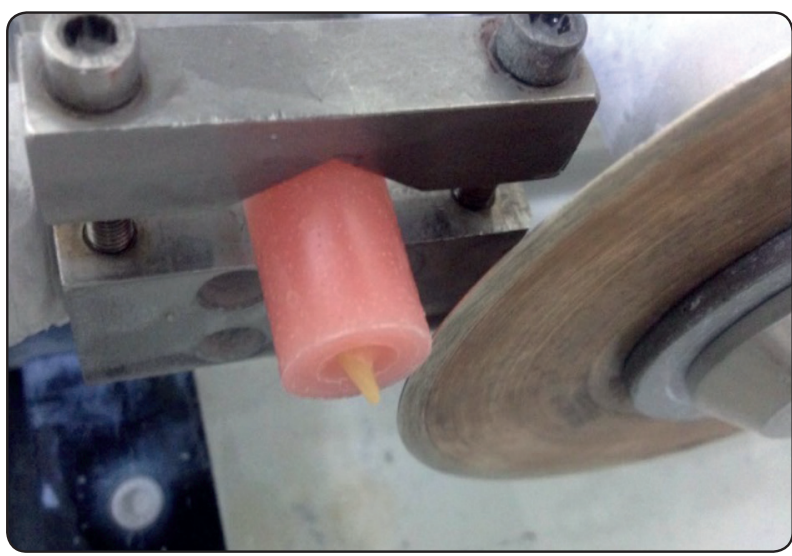

Fig. (3): Corcular diamond at low speed disc used in cutting the samples at different thirds

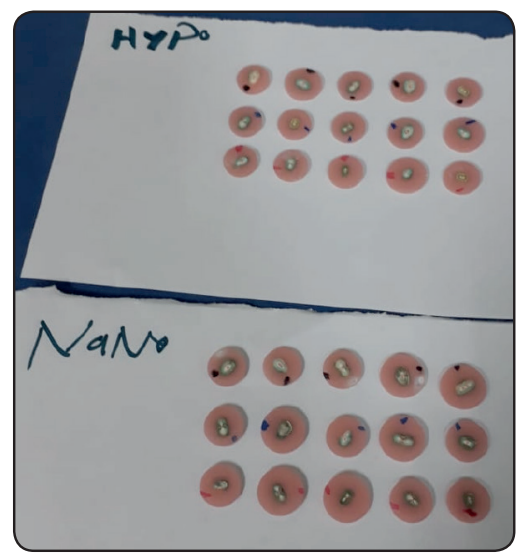

Fig. (5): Preparation of root slices at coronal, middle and apical thirds

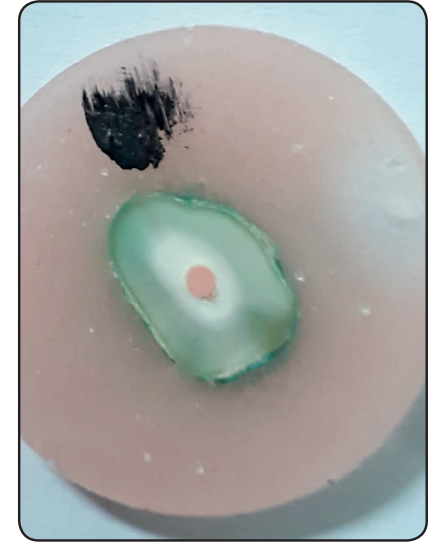

Fig. (2): Root sample after insertion in acrylic blocks

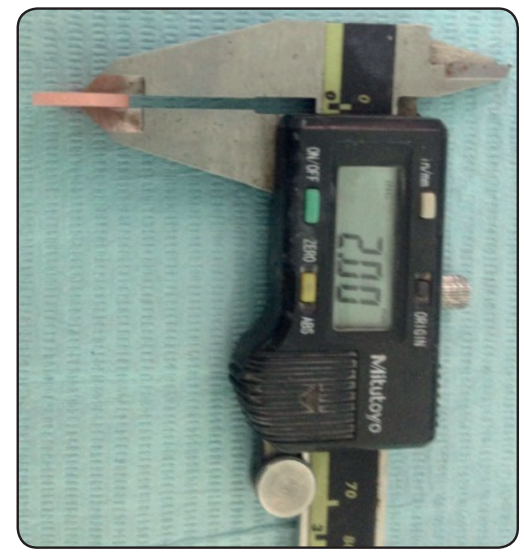

Fig. (4): Caliber checking $2 \mathrm{~mm}$ thickness of slices samples

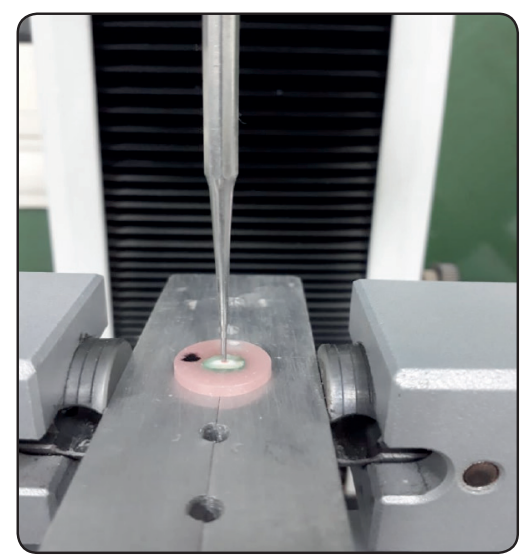

Fig. (6): $2 \mathrm{~mm}$ slice sample during push out bond strength test 
testing machine (Instron universal testing machine model 3345 England data recorded using computer software Bluehill 3 version 3.3). The samples were aligned over a support jig in an apical to coronal direction to avoid any constriction interference. The tests were conducted at a cross head speed of 0.5 min-1 using a $500 \mathrm{~N}$ load cell. The highest value recorded was taken as the push-out bond strength for each section.

The area under load was calculated by:

Area $=$ circumference of restoration $\times$ thickness.

The push-out value in MPa was calculated from force $(\mathrm{N})$ divided by area in $\mathrm{mm} 2$.

\section{RESULTS}

\section{Statistical analysis}

Data are expressed as mean \pm SD. Comparison between values of different parameters in two studied groups were performed using Kruskal Wallis ANOVA test followed by Mann-Whitney U test if significant results were recorded. Comparison between different variables in the two studied groups was performed using Mann-Whitney U test. Statistical Package for Social Sciences (SPSS) computer program (version 19 windows) was used for data analysis. $\mathrm{P}$ value $\leq 0.05$ was considered significant.
AH plus sealer showed a lower value of push out bond strength ( $1.223 \pm 0.533)$ in the group irrigated using nano silver than the second group irrigated with sodium hypochlorite $(2.321 \pm 0.650)$ at the coronal third with statistically significant difference $(\mathrm{P}=0.004)$, also at the middle third it showed a lower value $(1.732 \pm 0.899)$ than the sodium hypochlorite but with no statistically significant difference, and finally at the apical third it also a lower value of push out bond strength $(2.103 \pm 1.319)$ than the other group irrigated with $\mathrm{NaOCl}(5.045 \pm 1.397)$ with statistically significant difference $(0.001)$

AH plus sealer showed higher push out bond within the group treated with the nano silver irrigant at the apical third $(2.103 \pm 1.319)$ than the middle third $(1.732 \pm 0.899)$ which also showed higher push out bond strength $(1.223 \pm 0.533)$ than that at the coronal third but there was no statistically significant difference between them.

Also the value of the push out bond strength of the AH Plus sealer in the group treated with the $\mathrm{NaOcl}$ at the apical one third $(5.045 \pm 1.397)$ was higher than that in the middle third $(1.785 \pm 0.906)$ with statistically significant difference where the value in the middle third was less than that in the coronal third $(2.321 \pm 0.650)$ with no statistically significant difference between them, the apical third showed higher value of push out bond strength than the coronal third with statistically significant difference.

TABLE (1): Comparison between values of push out stresses (MPa) in the two studied groups measured at different locations.

\begin{tabular}{|l|c|c|c|c|}
\hline Site & Nano sliver & NaOCl & Z test & p value \\
\hline Middle & $1.732 \pm 0.899$ & $1.785 \pm 0.906$ & -0.152 & 0.879 \\
\hline Apical & $2.103 \pm 1.319$ & $5.045 \pm 1.397$ & -3.187 & $0.001^{*}$ \\
\hline Coronal & $1.223 \pm 0.533$ & $2.321 \pm 0.650$ & -2.883 & $0.004^{*}$ \\
\hline
\end{tabular}

Data are expressed as mean $\pm S D . p>0.05=$ not significant. ${ }^{*} p<0.05=$ significant. 
TABLE (2): Comparison between values of push out stresses(MPa) of different locations in the two studied groups.

\begin{tabular}{|l|c|c|c|c|c|}
\hline \multicolumn{1}{|c|}{ Site } & Middle third & Apical third & Coronal third & $\mathbf{c}^{2}$ test & p value \\
\hline Narrigant & $1.732 \pm 0.899$ & $2.103 \pm 1.319$ & $1.223 \pm 0.533$ & 4.019 & 0.134 \\
\hline NaOCI & $1.785 \pm 0.906$ & $5.045 \pm 1.397^{\mathrm{a}}$ & $2.321 \pm 0.650^{\mathrm{b}}$ & 17.690 & $0.001^{*}$ \\
\hline
\end{tabular}

Data are expressed as mean $\pm S D$. $c^{2}$ test $=$ Kruskal Wallis ANOVA test

${ }^{*} p<0.05=$ significant. ${ }^{a} p<0.05$ relative to middle. ${ }^{b} p<0.05$ relative to Apical.

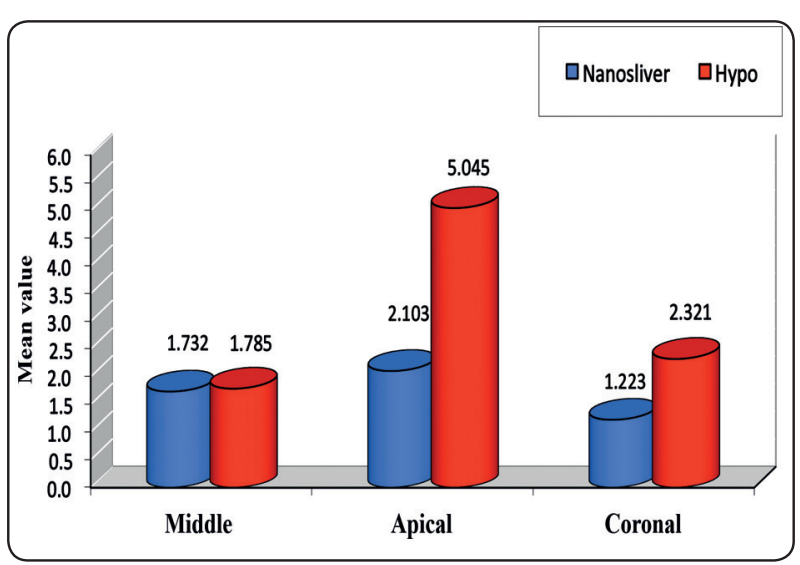

Fig. (7): Comparison between values of push out stresses $(\mathrm{MPa})$ in the two studied groups measured at different locations.

\section{DISCUSSION}

Several investigations reported the high quality properties of epoxy resin-based sealers, including very low shrinkage while setting, long-term dimensional stability, excellent flow property, deeper penetration into the dentinal tubules and surface micro-irregularities which all lead to strong bond to dentin. ${ }^{[25,26]}$

Epoxy resin-based AH Plus sealer has been extensively used with gutta percha because of its potential for better wettability of dentin and gutta percha, reduced solubility, very low shrinkage while setting, sealability, bonding and micro retention to the root dentin and adequate biological performance. Bonding of AH Plus sealer to dentin could be explained by the formation of a covalent

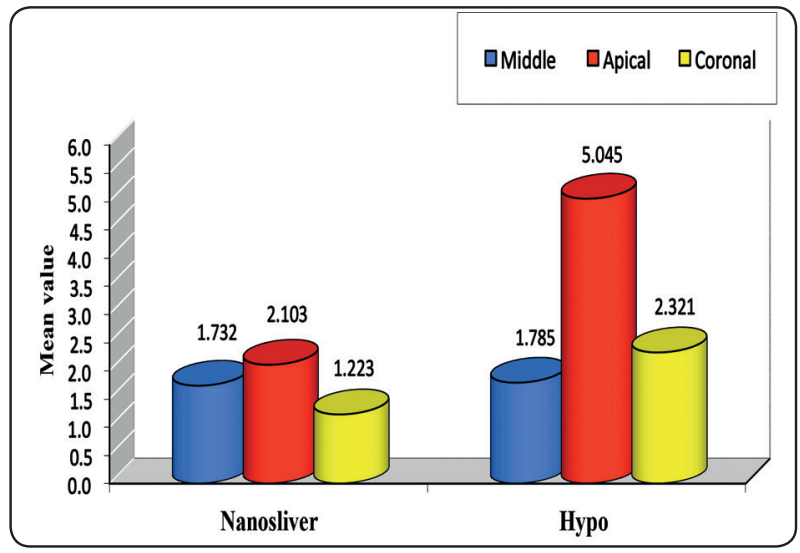

Fig. (8): Comparison between values of push out stresses (MPa) of different locations in the two studied groups.

bond by an open epoxide ring of $\mathrm{AH}$ Plus to any exposed amino groups in dentin collagen. ${ }^{[27,28,29]}$

According to Dogan $\mathrm{H}$ et al., adhesion of resin based sealer materials to the dentinal surfaces is affected by different irrigation regimens due to change in permeability and solubility characteristics of dentin caused by the usage of irrigants. ${ }^{[30]}$

Sodium hypochlorite $(\mathrm{NaOCl})$ is the most commonly used root canal irrigant because of its antibacterial effect and its ability to dissolve the organic debris and remaining pulp tissues. ${ }^{[6,7,8]}$

$\mathrm{NaOCl}$ can dissolve the organics components mainly collagens, which is helpful for the removal of smear layers and can expose the dentinal tubules, thus producing a clean dentin surface and improving the penetration of resin into the dentin structure 
facilitating the mechanical bonding. ${ }^{[31,32]}$ This might be the explanation of higher values of pushout bond strength results for the specimen groups irrigated with $\mathrm{NaOCl}$ compared to Nano-silver irrigant in all regions coronal, middle and apical thirds

According to Zhang et al, $\mathrm{NaOCl}$ solution has low molecular weight and can penetrate the apatiteencapsulated collagen matrix, removing the organic phase of the mineralized dentin. ${ }^{[33,34]}$

Another study concluded that there was no effect of $\mathrm{NaOCl}$ on bond strength. Morris et al. [35] found that the use of $\mathrm{NaOCl}$ led to reduction in the bond strength between resin and dentin. It is thought that $\mathrm{NaOCl}$ forms free radical layer due to oxidation of some of the dentin components these free radicals inhibits polymerization of adhesives lowering the bond strength. ${ }^{[36,37,38]}$

In another study, results showed that $\mathrm{NaOCl}$ and $\mathrm{Ca}(\mathrm{OCl}) 2$ solutions, when used alone, were unable to remove the smear layer. Previous investigations had already shown this performance for $\mathrm{NaOCl}$ showing that this solution is not able to act on the hydroxyapatite that obliterates the dentinal tubules after root canal instrumentation. This happened only in the group in which $\mathrm{NaOCl}$ was used without EDTA, the results were significantly different from those observed in groups irrigated with $\mathrm{NaOCl}$ before the use of EDTA. ${ }^{[34,39,40]}$

EDTA is widely used as a chelating agent and is able to react with calcium ions in hydroxyapatite crystals, removing calcium ion from the dentin. However, when $\mathrm{NaOCl}$ is associated with EDTA, alteration of the organic and inorganic dentin components and erosion are observed. ${ }^{[34,41,42,43]}$

Another explanation for the higher values of bond strength of $\mathrm{NaOCl}$ may be attributed to its low surface tension which facilitate better wettability to the dentin surface. The surface tension is a physical property caused by the cohesive force between similar molecules and is responsible for the phenomenon of capillarity and droplet formation. ${ }^{[44]}$
According to the findings of Leonardo et al, $\mathrm{Ca}(\mathrm{OCl})_{2}$ solution has higher surface tension when compared to $\mathrm{NaOCl}$ at the same concentration. Therefore, the fact that $\mathrm{Ca}(\mathrm{OCl})_{2}$ has a higher surface tension can cause less penetration into dentin, impairing the smear layer removal at the root canal apical third. ${ }^{[34,44]}$

Kutty S N et al declared that there are three types of reactions that take place due to the interaction of $\mathrm{NaOCl}$ with organic matter. These reactions take place mostly at the surface.1- Saponification reaction: $\mathrm{NaOCl}$ has several functions it dissolves fat and organic tissues, thus converting fatty acids into fatty acid salts (soap) and glycerol (alcohol), and reduces surface tension of the remaining solution. 2- Amino acid neutralization reaction: $\mathrm{NaOCl}$ reacts with amino acids to form salt and water, with a reduction of $\mathrm{pH}$ and exit of hydroxyl ions. Chloramination reaction: Hypochlorous acid $(\mathrm{HOCl})$ present in $\mathrm{NaOCl}$ solution is an organic tissue solvent. It releases chlorine, which form chloramines on reaction with amino group of proteins. Hypochlorous acid and hypochlorite ions (OCl-) cause amino acid degradation and hydrolysis. ${ }^{[45]}$

The dentin bond strength improvement that was observed after $\mathrm{NaOCl}$ irrigation has been attributed to its deproteinizing action. $\mathrm{NaOCl}$ dissolve dentinal collagen exposing fresh mineralized dentin surface that allows a direct bonding between resin and dentin. This came in agreement with Prati et al., who observed an unusual mechanism of micromechanical retention of resin into dentin that called "reverse hybrid layer formation". ${ }^{[46]}$

In order to form a conventional hybrid layer it is required to remove the smear layer by the aid of acid etching as well as mineralized dentin to expose collagen fibrils. The adhesive resin will infiltrates around the exposed collagen fibrils and replace lost mineral phase. $\mathrm{NaOCl}$ irrigation after acid etching will remove the exposed collagen and dissolve fibrils of underlying mineralized matrix creating submicron porosities within the mineral phase. Therefore resin 
will infiltrate these submicron porosities, forming a layer of resin-infiltrated mineralized matrix. ${ }^{[46]}$ Furthermore, the removal of exposed collagen does not only reduce the bonding technique sensitivity but also produce a more porous surface, an increase in size of dentinal tubules with the presence of an extensive labyrinth of lateral tubules that open on intertubular and/or peritubular dentin and larger resin tags that would produce interfaces with high bond strength. The use of $\mathrm{NaOCl}$ also produced an acid-base resistant zone under the hybrid layer this zone could help in resisting secondary caries around restorations ${ }^{[46-48]}$.

Silver nanoparticles irrigant showed lower values in push out bond strength test than $\mathrm{NaOCl}$ in all specimens which may be attributed to their effect in occluding the dentinal tubules by the AgNP. This may be in agreement with Fan et al in their study at 2014 in which they used silver mesoporous $\mathrm{Ca}-\mathrm{Si}$ nanoparticles which possess both the merits of mesoporosity and the capability to release $\mathrm{Ca}$ and silicic acid ions as antibacterial reagents. They found out from the images acquired by FE-SEM that the use of $\mathrm{Ca}(\mathrm{OH})_{2}$, suspension led to clean dentinal tubule orifices on the canal wall. After passive ultrasonic treatment with Ag-MCSNs suspension, they found numerous nanoparticles aggregated around the tubular orifice and infiltrated the dentinal tubules even after canal rinsing. ${ }^{[49]}$

Earl et al at 2009 used Nano-sized particles of hydroxyapatite, produced by a hydrothermal synthesis technique for trials of dentinal tubule infiltration in etched sections of clinically extracted human molars. They found that, up to $90 \%$ of the tubules were being fully or partially occluded. Information on the depth of infiltration was obtained from sections of dentine prepared using focused ion beam milling (FIB-SEM). ${ }^{[50]}$

The middle and apical thirds of the root canals were analyzed because they are the most critical thirds to be reached and cleaned during root canal treatment, as compared to the cervical third ${ }^{[34,51]}$.
The apical third results showed the higher bond strength values in comparison to the middle and coronal thirds. This may be attributed to that, this area is difficult to be reached with irrigants minimizing the adverse effect of $\mathrm{NaOCl}$ on resin sealers and the obliterating effect of dentinal tubules by silver nanoparticles. ${ }^{[34]}$

\section{CONCLUSION}

Within the limitation of this study, it is recommended when using an antimicrobial irrigants $\mathrm{NaOCl}$ is preferred than silver nanoparticles irrigant concerning their effect on bond strength between the sealer and dentin.

\section{REFERENCES}

1. Lotfi M, VosoughhosseiniS, Ranjkesh B, Khani S, Saghiri $\mathrm{M}$ and Zand V. Antimicrobial efficacy of nanosilver, sodium hypochlorite and chlorhexidine gluconate against Enterococcus faecalis. Afr. J. Biotechnol. 2011; 10(35): 6799-6803.

2. Topbas C, Adiguzel O. Endodontic irrigation solutions: A Review. Int Dent Res. 2017; 7: 54-61.

3. Tawakoli1 P. N, Ragnarsson K. T, Rechenberg D. K, Mohn $\mathrm{D}$ and Zehnder M. Effect of endodontic irrigants on biofilm matrix polysaccharides. International Endodontic Journal. 2017; 50: 153-160.

4. Moghadas L, Shahmoradi M, Narimani T. Antimicrobial activity of a new nanobased endodontic irrigation solution: In vitro study. Dent Hypotheses 2012; 3: 142-6.

5. Haapasalo M, Shen Y, Qian W, Gao Y. Irrigation in endodontics. Dent Clin North Am. 2010; 54: 291-312

6. Chan E L, Zhang C, Cheung G S. Cytotoxicity of a novel nano-silver particle endodontic irrigant. Clin Cosmet Investig Dent. 2015; 7: 65-74.

7. Morgental R.D, Singh A, Sappal H, Kopper P.M.P, Vier-Pelisser F.V, and Peters O.A. Dentin inhibits the antibacterial effect of new and conventional endodontic irrigants. Journal of Endodontics. 2013; 39:406-410.

8. Rodrigues CT, de Andrade FB, de Vasconcelos LRSM, Midena RZ, Pereira TC, Kuga MC, Duarte MAH, Bernardineli N. Antibacterial properties of silver nanoparticles as a root canal irrigant against Enterococcus faecalis biofilm and infected dentinal tubules. International Endodontic Journal. 2018; 51, 901-911. 
9. Rai MK, Deshmukh SD, Ingle AP, Gade AK. Silver nanoparticles: the powerful nanoweapon against multidrugresistant bacteria. Journal of Applied Microbiology. 2012; 112: 841-52.

10. Shrestha A, Kishen A. Antibacterial nanoparticles in endodontics: a review. Journal of Endodontics.2016; 42: 1417-26.

11. Silver S, le Phung T, Silver G. Silver as biocides in burn and wound dressings and bacterial resistance to silver compounds. Journal of Industrial Microbiology \& Biotechnology.2006; 33: 627-34.

12. Kishen A, Shi Z, Shrestha A, Neoh KG. An investigation on the antibacterial and antibiofilm efficacy of cationic nanoparticulates for root canal disinfection. Journal of Endodontics. 2008; 34: 1515-20.

13. Monzavi A, Eshraghi S, Hashemian R, and Momen-Hervi F. In vitro and ex vivo antimicrobial efficacy of nano- $\mathrm{MgO}$ in the elimination of endodontic pathogens. Clinical Oral Investigations. 2015; 19:349-356.

14. Allaker RP, Memarzadeh K. Nanoparticles and the control of oral infections. International Journal of Antimicrobial Agents.2014; 43: $95-104$.

15. Degrazia FW, Leitune VC, Garcia IM, Arthur RA, Samuel SM, Collares FM. Effect of silver nanoparticles on the physicochemical and antimicrobial properties of an orthodontic adhesive. Journal of Applied Oral Science. 2016; 24: 404-10.

16. Javidi M, Afkhami F, Zarei M, Ghazvini K, Rajabi O. Efficacy of a combined nanoparticulate/calcium hydroxide root canal medication on elimination of Enterococcus faecalis. Australian Endodontic Journal. 2014; 40: 61 -5.

17. Luna P G, Castañón G A M, Alonso N V Z, Marin N P, Martínez N N, Martínez J M, and González J H R. Bactericide Effect of Silver Nanoparticles as a Final Irrigation Agent in Endodontics on Enterococcus faecalis: An Ex Vivo Study. Journal of Nanomaterials. 2016; ID 7597295: 1-7. http://dx.doi.org/10.1155/2016/7597295

18. Ozkocak I, Sonat B. Evaluation of effects on the adhesion of various root canal sealers after Er: YAG laser and irrigants are used on the dentin surface. Journal of endodontics. 2015; 41:1331-6.

19. Yavari H, Ghasemi N, Divband B, Rezaei Y, Jabbari G, Payahoo S. The effect of photodynamic therapy and polymer solution containing nanoparticles of $\mathrm{Ag} / \mathrm{ZnO}$ on push-out bond strength of the sealers AH-Plus and MTA Fillapex. J Clin Exp Dent. 2017; 9(9):e1109-14.
20. Eldeniz AU, Erdemir A, Belli S. Shear bond strength of three resin based sealers to dentin with and without the smear layer. Journal of Endodontics. 2005; 31: 293-6.

21. Akcay M, Arslan H, Topcuoglu HS, Tuncay O. Effect of calcium hydroxide and double and triple antibiotic pastes on the bond strength of epoxy resin-based sealer to root canal dentin. Journal of endodontics. 2014;40:1663-7.

22. Topçuoğlu HS, Tuncay Ö, Demirbuga S, Dinçer AN, Arslan H. The Effect of Different Final Irrigant Activation Techniques on the Bond Strength of an Epoxy Resinbased Endodontic Sealer: A Preliminary Study. Journal of endodontics. 2014; 40: 862-6.

23. Celik D, Er K, Serper A, Taşdemir T, Ceyhanlı KT.Pushout bond strength of three calcium silicate cements to root canal dentine after two different irrigation regimes. Clin Oral Investig 2014; 18(4): 1141-6.

24. Farag H A and Darrag A M. Effect of different irrigating protocols on push out bond strength of Resilon/Epiphany obturation system. Tanta Journal.2015; 12 (4): 241-248.

25. Patil S A, Dodwad P K, Patil A A. An in vitro comparison of bond strengths of Gutta-percha/AH Plus, Resilon/ Epiphany self-etch and EndoREZ obturation system to intraradicular dentin using a push-out test design. J Conserv Dent. 2013; 16: 238-42.

26. Neelakantan P, Sharma S, Shemesh H, and Wesselink P. Influence of Irrigation Sequence on the Adhesion of Root Canal Sealers to Dentin: A Fourier Transform Infrared Spectroscopy and Push-out Bond Strength Analysis. J Endod. 2015; 41: 1108-11.

27. Nunes VH, Silva RG, Alfredo E, Sousa-Neto MD, SilvaSousa YT. Adhesion of Epiphany and AH Plus sealers to human root dentin treated with different solutions. Braz DentJ 2008; 19: 46-50.

28. Versiani MA, CarvalhoJuniorJR, Padilha MI, Lacey S, Pascon EA, SousaNeto [8] MD. A comparative study of physicochemical properties of AH Plus and Epiphany root canal sealants. Int Endod J. 2006;39:464-71.

29. Kamalasanan R R, Devarasanahalli S V, Swathanarayana R M, Rashmi K, Gowda Y S, Dig R R. Effect of 5\% Chlorine Dioxide Irrigant on Micro Push Out Bond Strength of Resin Sealer to Radicular Dentin: An In Vitro Study. Journal of Clinical and Diagnostic Research. 2017; 11(5): 49-53.

30. Dogan H, Oalt S. Effects of chelating agents and sodium hypochlorite on mineral [9] content of root dentin. J Endod. 2001; 27: 578-80. 
31. Yu H, Zhang L, Xu S, Li F, Yu F, Liu Z, Huang L \& Chen J. Effects of Epigallocatechin-gallate (EGCG) on the bond strength of fiber posts to Sodium hypochlorite $(\mathrm{NaOCl})$ treated intraradicular dentin. Scientific Reports. 2017; 7 : 4235. DOI:10.1038/s41598-017-04107-8: 1-7.

32. Chaudhary A, Kumar M, Taneja S. Evaluation of the effect of Calcium Hydroxide and endodontic irrigants on the push-out bond strength of fiber post- An in vitro study. Clujul Medical. 2018; 91(4): 458-461.

33. Zhang, K., Tay, F. R., Kim, Y. K., Mitchell, J. K., Kim, J. R., Carrilho, M., Ling, J. Q. (2010). The effect of initial irrigation with two different sodium hypochlorite concentrations on the erosion of instrumented radicular dentin. Dental Materials, 26, 514-523.

34. Cardoso L R, Baldasso F E R, Delai D, Montagner F, Kopper P M P. Effect of EDTA, sodium, and calcium hypochlorite on the inorganic component of root canal dentin: A SEM analysis. wileyonlinelibrary.com/journal/ jemt. Microsc Res Tech. 2018; 1-6.

35. Morris MD, Lee KW, Agee KA, Bouillaguet S, Pashley DH. Effects of sodium hypochlorite and RC-prep on bond strengths of resin cement to endodontic surfaces. J Endod. 2001; 27(12): 753-7.

36. Endo T, Osada T, Finger WJ, Hoffmann M, Kanehira M, Komatsu M. Effect of oxygen inhibition of self-etching adhesives on enameldentin polymer bond. J Adhes Dent. 2007; 9(1):33-8.

37. Wattanawongpitak N, Nakajima M, Ikeda M, Foxton RM, Tagami J. Microtensile bond strength of etch-andrinse and self-etching adhesives to intrapulpal dentin after endodontic irrigation and setting of root canal sealer. J Adhes Dent. 2009; 11(1): 57-64.

38. Mokhtari F, Anvar E, Mirshahpanah M, Hemati H, Kazemi A D. The Probable Effect of Irrigation Solution and Time on Bond Strength to Coronal Dentin: An In Vitro Evaluation. IEJ Iranian Endodontic Journal 2017; 12(4): 439-442.

39. Moreira, D. M., Almeida, J. F., Ferraz, C. C., Gomes, B. P., Line, S. R., \& Zaia, A. A.. Structural analysis of bovine root dentin after use of different endodontics auxiliary chemical substances. Journal of Endodontics. 2009; 35: 1023-1027.

40. Ghisi, A. C., Kopper, P. M. P., Baldasso, F. E., Stürmer, C. P., Rossi-Fedele, G., Steier, L., ... Vier-Pelisser, F. V. Effect of superoxidized water and sodium hypochlorite, associated or not with EDTA, on organic and inorganic components of bovine root dentin. Journal of Endodontics. 2015; 41: 925-930.

41. Calt S, \& Serper A. Time-dependent effects of EDTA on dentin estructures. Journal of Endodontics. 2002; 28: 17-19.

42. Lottanti S, Gautschi H, Sener B, \& Zehnder M. Effects of ethylenediaminetetracetic, etidronic and peracetic acid irrigation on human root dentine and the smear layer. International Endododontic Journal.2009; 42: 335-343.

43. Baldasso F E R, Cardoso L R, da Silva V D, Morgental R D \& Kopper P M P. Evaluation of the effect of four final irrigation protocols on root canal dentin components by polarized light microscopy and scanning electron microscopy. Microscopic Research \& Technique. 2017; 80: 1337-1343.

44. Leonardo N G, Carlotto I B, Luisi S B, Kopper P M, Grecca F S \& Montagner F. Calcium hypochlorite solutions: Evaluation of surface tension and effect of different storage conditions and time periods over $\mathrm{pH}$ and available chlorine content. Journal of Endodontics.2016; 42: 641-645.

45. Kutty S N, Lekshmi M S, Aparna M E and Isaac L. Pulp tissue dissolution in endodontics- A review. International Journal of Applied Dental Sciences. 2017; 3(2): 193-196]

46. Prati C, S. Chersoni, and D. H. Pashley, "Effect of removal of surface collagen fibrils on resin-dentin bonding," Dental Materials,vol.15,no.5,pp.323-331,1999.

47. Francescantonio M D, Nurrohman H, Takagaki T, Nikaido T, Tagami J and Giannini M. Sodium hypochlorite effects on dentin bond strength and acid-base resistant zone formation by adhesive systems. Brazilian Journal of Oral Sciences.2015;14(4):334-340.

48. Abuhaimed T S and AbouNeel E A. Sodium Hypochlorite Irrigation and its Effect on Bond Strength to Dentin. BioMed Research International. 2017; Article ID 1930360, 1-8.

49. Fan W. Wu D, Tay F R, Ma T, Wu Y, and Fan B. Effects of adsorbed and templated nanosilver in mesoporous calciumsilicate nanoparticles on inhibition of bacteria colonization of dentin. Int J Nanomedicine. 2014; 9: 5217-5230.

50. Earl J S, Wood D J and Milne S J.Nanoparticles for Dentine Tubule Infiltration: An In Vitro Study. Journal of Nanoscience and Nanotechnology.2009; 9(11): 6668-6674

51. Lyra, C. M., Delai, D., Pereira, K. C. R., Pereira, G. M., Pasternak-Júnior, B., \& Oliveira, C. A. P. (2015). Morphology of mesiobuccal root canals of maxillary first molars: A comparison of CBTC scanning and crosssectioning. Brazilian Dental Journal, 26, 525-529. 